Research Article

\title{
Determination of Water-Proof Coal (Rock) Pillar Height in Mining Coal Seam Group under Water-Bearing Rock Stratum
}

\author{
Feng Wan (iD, Hongqing Zhang, Peijun Zhou, and Jie Guo \\ Zhalainuoer Coal Industry Co.,Ltd., Manzhouli 021410, China \\ Correspondence should be addressed to Feng Wan; 3368675365@qq.com
}

Received 31 December 2020; Revised 28 January 2021; Accepted 1 February 2021; Published 16 February 2021

Academic Editor: Guangchao Zhang

Copyright (c) 2021 Feng Wan et al. This is an open access article distributed under the Creative Commons Attribution License, which permits unrestricted use, distribution, and reproduction in any medium, provided the original work is properly cited.

\begin{abstract}
In order to determine the reasonable height of water-proof coal (rock) pillar when mining multiple coal seams under aquifer, this paper analyzes the expansion height of water-conducting fracture zone when coal seams mining. Considering the expansion law of water-conducting fracture zone in coal seams mining, two schemes of coal seams mining in upper and lower groups and one-time mining of all coal seams are designed for comparative analysis, and the height of water-proof coal (rock) pillar is determined based on the expansion height of water-conducting fracture zone. The results show that the height of water-proof coal (rock) pillar is calculated as $91.08 \mathrm{~m}$ when mining upper and lower groups and $105.46 \mathrm{~m}$ when mining all coal seams at the same time. According to UDEC numerical simulation results, the height of water-proof coal (rock) pillar is $56.08 \mathrm{~m}$ when mining upper and lower groups and $86.36 \mathrm{~m}$ when mining all coal seams at the same time. Comparing the results of theoretical calculation and numerical analysis, the maximum value is selected as the final result, and the reasonable water-proof coal (rock) pillar height is determined to be $105.46 \mathrm{~m}$
\end{abstract}

\section{Introduction}

After underground coal seam mining, the migration and destruction of overlying strata will form a hydraulic connection channel between stope and surrounding waterbearing rock stratum, which threatens the safety of mine production. By studying the height of water-conducting fracture zone in overlying strata, preventive measures can be taken to avoid mine water disasters. In recent years, methods for determining the height of water-conducting fracture zone, such as geophysical prospecting, high-density resistivity method, transient electromagnetic method, and borehole peeping method, have been developed [1-5], and many researchers have done a lot of research and obtained very fruitful results [6-13]. Jiang [14] established the "rock quality index" method for water-conducting fracture zone prediction. Zhao et al. [15] analyzed the height of waterconducting fracture zone under special conditions such as full-mechanized caving mining and full-seam mining based on the theory of internal and external stress fields. Xu [16] put forward the concept of "effective water-proof thickness."
Gao [17] established the "four zones" model of strata movement. Zhang et al. [18] established the physical model of "mining-bursting" and the relationship between mining kinetic energy and strain energy and determined the relationship between the safe distance of rock blasting and the height of water-conducting fracture zone. Jia et al. [19] analyzed the distribution range of mining fault zone in steep working face and determined the reasonable width of waterproof coal (rock) pillar. Huang et al. [20] proposed a new method for predicting the height of water-conducting fracture zone based on the calculation of overburden composite structure and rock tensile deformation. Yu et al. [21] analyzed the maximum caving height and effective water guide height of overlying strata under different mining-caving ratios. Many researchers used numerical simulation to verify theoretical results. Tang et al. [22] used RFPA system to simulate the dynamic development process of water-conducting fractured zone. Yin [23] simulated and analyzed the stress evolution of surrounding rock in advancing of different mining faces based on FLAC3D numerical method. Li et al. [24] used FLAC to study the height 
of water-conducting fracture zone in coal mining face under water-rich extra-thick glutenite. Xu et al. [25, 26] quantitatively analyzed the model of mining fracture propagation based on FIMAGE. Yang et al. [27] used UDEC to study the influence of mining sequence of multiple coal seams under rivers on the development height of water-conducting fracture zone in overlying strata.

Reasonable height of water-proof coal (rock) pillar can effectively inhibit the development of water-conducting fracture zone of overlying strata in mining field and ensure that the working face is not threatened by water disasters during mining. However, because of the complex geological conditions in coal mines, there is no consistent standard for determining the size of water-proof coal (rock) pillar. For example, the formula of water-proof coal (rock) pillar applied in Europe earlier [28] only considers the influence of water pressure and coal seam thickness on coal pillar, but ignores the determination of coal pillar by coal strength and buried depth. Based on the pressure arch, the formula [29] for determining water-proof coal (rock) pillar is only applicable to coal seams with a buried depth of 400-2800 feet. The early formula of water-proof coal (rock) pillar applied in the United States [30] ignores the influence of water pressure and caving zone, and the calculated water-proof coal (rock) pillar size is too small. Wang gives the observation equation of water-proof coal (rock) pillar according to the abovementioned problems [31]. In recent years, some achievements have been made in the research on the height of water-proof coal (rock) pillar in coal mines in China. The representative ones are Shi et al. [32], who deduced the formula of waterproof coal (rock) pillar in stope fault based on the comprehensive factors of mine pressure. Peng et al. [29], aiming at different fault dip angles, obtained the formulas of waterproof coal (rock) pillar with different widths by using fluid mechanics, elastoplastic limit equilibrium theory, and soil mechanics theory.

Analysis of the development law of water-conducting fractured zone under multiple coal seams is of great significance for multiseam mining under aquifer. From the foregoing analysis, it can be seen that there is a lack of relevant research on the development law of water-conducting fracture zone in multiseam mining under waterbearing stratum. In view of the potential danger of waterbearing stratum in multiseam mining, this paper analyzes the development height of water-conducting fracture zone in multiseam mining by theoretical analysis and UDEC numerical simulation and further designs reasonable waterproof coal (rock) pillar height to provide basis for on-site safety production.

\section{Background of the Project}

The length of a coal mine from east to west is about $9.3 \mathrm{~km}, 1.3 \sim 3.1 \mathrm{~km}$ wide from north to south, covering an area of $22.41 \mathrm{~km}^{2}$, with a designed production capacity of $1.2 \mathrm{Mt} / \mathrm{a}$ and a service life of $60.5 \mathrm{a}$. The whole mine field is monoclinic structure, with 11 faults in the whole mine field, only one fault with a fall greater than $30 \mathrm{~m}$, and the dip angle is $4^{\circ} \sim 24^{\circ}$, so the stratigraphic structure is relatively simple. There are 7 layers of minable coal seams in the whole area, most parts and parts of the mine field, which are numbered as nos. 13, 12, 10, 9, 8-3, 8-2, and 8-1 from bottom to top. The total thickness of minable coal seams is $21.92 \mathrm{~m}$, and the dip angle of coal seams is between $4^{\circ}$ and $24^{\circ}$, which belongs to nearly horizontal coal seams. According to the field hydrogeology survey, the pore fissure water-bearing rock stratum overlying 8-1 coal has a pressure head of $0.44 \mathrm{MPa}$, and its thickness is $64.91 \sim 158.00 \mathrm{~m}$, with an average thickness of $116.48 \mathrm{~m}$ revealed by 44 boreholes. The unit water inflow in the water-bearing rock stratum mine field is $0.1 \mathrm{l} /$ s.m $<q<1.001 / \mathrm{s} . \mathrm{m}$, and the permeability coefficient is $0.0469 \sim 0.2288 \mathrm{~m} / \mathrm{d}$, which belongs to medium water-rich property and is the main water filling source for coal mining. At the bottom boundary of tertiary system, variegated mudstone was formed after weathering of middle and lower Jurassic strata, with an average thickness of $10.3 \mathrm{~m}$, which is a good natural water-proof strata.

The above stratum structure features have both advantaged and disadvantaged factors for mining coal seam group under water-bearing rock stratum. The advantaged factor is that there is no hydraulic connection between the effective water-bearing rock strata of bedrock, the relative waterproof strata, and the weak water-bearing rock stratum in the area, because there are thick multilayer argillaceous waterproof strata. The disadvantaged factor is that the roof and floor of minable seam are extremely unstable and soften strongly when meeting water, so it is necessary to analyze the height of water-conducting fracture zone and determine the water-proof coal (rock) pillar.

\section{Determination of Height of Water- Conducting Fracture Zone}

The water-conducting fracture zone refers to the sum of caving zone and fracture zone of overlying strata in goaf. The saturated uniaxial compressive strength of roof and floor strata of the coal mine is within $40 \mathrm{MPa}$, and the roof and floor strata in this area are medium hard strata. When there are extremely hard strata in the overlying strata of coal seam roof, the suspended roof can be formed after mining, and the formula of caving zone is

$$
H_{m}=\frac{M}{(K-1) \cos \alpha},
$$

where $H_{m}$ is the maximum caving zone height; $M$ is the thickness of coal seam mining; $K$ is the crushing expansion coefficient of caving rock, and $\alpha$ is the dip angle of coal seam.

At present, when determining the water-conducting fracture zones with different overlying strata lithology in gently inclined and inclined thick coal seams in China, the calculation is mainly based on the formula in Regulations for Coal Pillar Retention and Coal Mining in buildings, water bodies, railways, and main roadways [33]. Determine the formula of water-conducting fracture zone in minable seam of this coal mine as follows: 


$$
\begin{aligned}
& H_{l i}=\frac{100 \sum M}{1.6 \sum M+3.6} \pm 5.6, \\
& H_{l i}=\sqrt[20]{\sum M+10}
\end{aligned}
$$

where $H_{l i}$ is the height of water-conducting fracture zone and $M$ is the thickness of coal seam mining.

In water-conducting fracture zone calculation, the smaller the coal seam thickness, the smaller the expansion height of water-conducting fracture zone, and the greater the coal seam thickness, the greater the expansion height of water-conducting fracture zone. According to the coal seam occurrence conditions in the preliminary design of the mine, the following two schemes are designed when determining the height of water-conducting fracture zone.

Grouping mining: calculate the expansion height of waterconducting fracture zone according to the mining of upper and lower coal groups. The upper coal group includes 8-1 coal seam, 8-2 coal seam, 8-3 coal seam, 9 coal seam, and 10 coal seam, and the lower coal group includes 12 coal seam and 13 coal seam. In the calculation process of the lower coal group, firstly calculate the height of the caving zone, determine whether the caving zone affects the overlying coal seam, and then calculate the expansion height of water-conducting fracture zone according to the relevant formula.

Simultaneous mining of all coal seams: calculate the expansion height of water-conducting fracture zone according to one-time mining of all coal seams.

3.1. Determination of Height of Water-Conducting Fracture Zone by Grouping Mining. The total thickness of the lower group coal is $5.6 \mathrm{~m}$, the dip angle of coal seam is $14^{\circ}$, and the crushing expansion coefficient is taken as 1.3. According to formula (1), the height of water-conducting fracture zone in the lower group coal mining is $19.2 \mathrm{~m}$, and the distance between the lower group coal 12 and the upper group coal 10 is about $124.6 \mathrm{~m}$, so the caving zone in the lower group coal mining cannot reach the upper group coal range. According to formula (2), the height of water-conducting fracture zone of lower group coal is calculated to be $50.2 \mathrm{~m}$, and formula (3) is calculated to be $57.2 \mathrm{~m}$. The maximum value of calculation results is selected, and the height of water-conducting fracture zone is determined to be $57.2 \mathrm{~m}$ when the lower group coal is produced.

The total thickness of the upper group coal is $12.6 \mathrm{~m}$, and the height of water-conducting fracture zone of the upper group coal is calculated as $58.6 \mathrm{~m}$ according to formula (2) and $81 \mathrm{~m}$ according to formula (3). The maximum value of calculation results is selected, and it is determined that the height of water-conducting fracture zone is $81 \mathrm{~m}$, when the upper group coal is produced. Figure 1 shows the schematic diagram of the height of water-conducting fractured zone in grouping mining.

3.2. Determination of Height of Water-Conducting Fracture Zone by Simultaneous Mining of All Coal Seams. Total height of recoverable thickness of 7 layers of coal is $18.1 \mathrm{~m}$.
According to formula (2), the height of water-conducting fracture zone is calculated as $61.2 \mathrm{~m}$ and that of waterconducting fracture zone is calculated as $95.1 \mathrm{~m}$ according to formula (3). Figure 2 shows the schematic diagram of height of water-conducting fracture zone in simultaneous mining of all coal seams.

\subsection{Determination of Height of Water-Proof Coal (Rock)} Pillar. According to the article [33], it is stipulated that when the outcrop of coal seam is covered by a loose waterbearing rock stratum with strong water-rich property (as shown in Figure 3), water-proof coal (rock) pillar should be retained to prevent the water-conducting fracture zone from penetrating through the water body, so the thickness of the water-proof coal (rock) pillar should be greater than or equal to the sum of the height of the water-conducting fracture zone and the thickness of the water-proof protective rock stratum, that is,

$$
H_{f} \geq H_{L}+H_{b}
$$

where $H_{f}$ is the water-proof coal (rock) pillar; $H_{L}$ is the water-conducting fracture zone; $H_{b}$ is the water-proof protective rock stratum; and $\alpha$ is the coal seam dip angle.

The accumulated mining thickness of 7 layers of coal is $18.1 \mathrm{~m}$, and the average thickness of mudstone waterresisting strata is $10.3 \mathrm{~m}$. According to [33], the height of water-proof protective rock stratum of medium hard overlying strata should be taken as $4 \mathrm{~A}$ according to the formula

$$
A=\frac{\sum M}{n} .
$$

The formula $\sum M$ is the accumulated mining thickness; $n$ is the number of layered layers.

The calculated $A=2.59$. According to formula (5), the thickness of water-proof protective rock stratum of grouping mining is $10.08 \mathrm{~m}$, and the thickness of water-proof protective rock stratum of simultaneous mining of all coal seams is $10.36 \mathrm{~m}$.

According to formula (4), it is determined that the height of water-proof coal (rock) pillar of grouping mining is $91.36 \mathrm{~m}$, and the height of water-proof coal pillar of simultaneous mining of all coal seams is $105.46 \mathrm{~m}$.

\section{UDEC Simulation Analysis}

Considering that the roof and floor of coal seam are mainly unstable sandstone-like strata, after being affected by mining, cracks develop upward along the weak surface of fault, which poses a great threat to mine water filling. At present, there is little research on the evolution law of caving zone of coal seam group under water-bearing strata. In view of the fact that discrete element software can vividly simulate the phenomena of separation and caving between strata, typical discrete element software UDEC is used to simulate and analyze the development height of water-conducting fracture zone. 


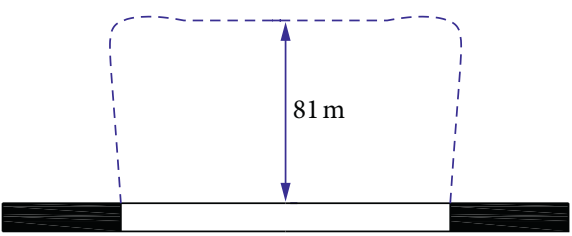

(a)

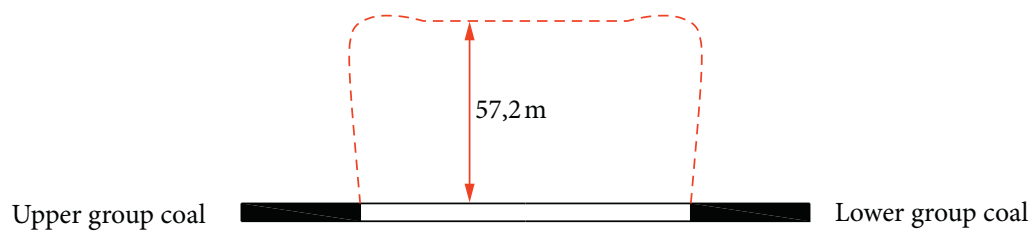

(b)

Figure 1: Expansion height of water-conducting fracture zone in grouping mining. (a) Expansion height of water-conducting fracture zone in the upper group coal mining. (b) Expansion height of water-conducting fracture zone in the lower group coal mining.

All coal seams

FIGURE 2: Expansion height of water-conducting fracture zone in simultaneous mining of all coal seams.

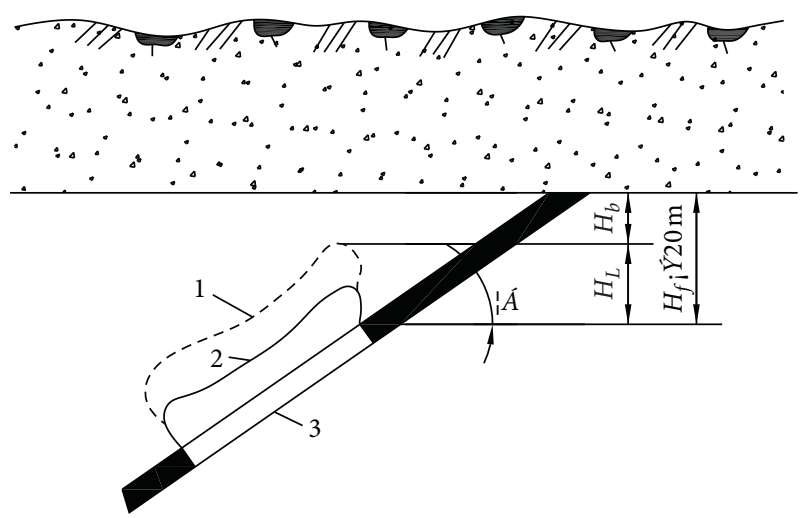

Figure 3: The coal seam outcrops were left pictures of water-proof coal (rock) pillar covered with loose, water-rich, and powerful water-bearing rock formations. (1) Water-conducting fracture zone. (2) Water-proof protective rock stratum. (3) Seam floor.

4.1. Establishment of Numerical Model. Based on the occurrence state of coal seams, it is considered that when all coal seams are built in the same model in the simulation results, because the whole thickness of the model is large and the thickness of a single coal seam is small, the simulation results cannot effectively display the range of water-conducting fracture zone. Therefore, in the establishment of the model, the range of model will be narrowed, the specific range of overlying strata caving in coal seam mining will be highlighted, and the models of two mining methods will be established. The mechanical parameters of coal and rock used in modeling are shown in Table 1.

4.1.1. Numerical Model of Grouping Mining. According to coal seam occurrence conditions, all minable coal seams are divided into upper and lower groups of coal. The upper group of coal includes 8-1 coal seam, 8-2 coal seam, 8-3 coal seam, 9 coal seam, and 10 coal seam, and the lower group of coal seam includes 12 coal seam and 13 coal seam.

(1) Numerical Model of Upper Group Coal Mining. The total thickness of the upper coal group is $12.5 \mathrm{~m}$, and the model range includes $20 \mathrm{~m}$ siltstone in the lower part of the coal seam, $40 \mathrm{~m}$ fine sandstone, $50 \mathrm{~m}$ siltstone, and $8 \mathrm{~m}$ mudstone, and the water-bearing rock stratum is above the mudstone. The rock layer about $457 \mathrm{~m}$ above the model is applied to the upper surface of the model in the form of vertical stress. The average bulk density of overlying strata is $23 \mathrm{kN} / \mathrm{m}^{3}$, and the applied vertical stress is $10.5 \mathrm{MPa}$. The model strike length is $400 \mathrm{~m}$, and the mining design model is shown in Figure 4.

(2) Numerical Model of Lower Group Coal Mining. The mining thickness of the lower group of coal is $5.6 \mathrm{~m}$, and the model range includes $27 \mathrm{~m}$ coarse sandstone in the lower part of coal seam, with $100 \mathrm{~m}$ glutenite overlying it. The rock layer about $671 \mathrm{~m}$ above the model is applied to the upper surface of the model in the form of vertical stress. The average bulk density of overlying strata is $23 \mathrm{kN} / \mathrm{m}^{3}$, and the applied vertical stress is $15.4 \mathrm{MPa}$. The strike length of the model is $400 \mathrm{~m}$, and the mining design model is shown in Figure 5.

4.1.2. Numerical Model of Simultaneous Mining of All Coal Seams. According to the occurrence conditions of coal seams, all minable coal seams are taken as a group of coal for mining design. In the model, the total thickness of coal seam is $18.1 \mathrm{~m}$, and the model range includes $15 \mathrm{~m}$ siltstone in the lower part of coal seam, covered with $40 \mathrm{~m}$ fine sandstone, $50 \mathrm{~m}$ siltstone, and $8 \mathrm{~m}$ mudstone, and the above mudstone is the water-bearing rock stratum range. The rock layer $457 \mathrm{~m}$ above the model is applied to the upper surface of the model in the form of vertical stress. The average bulk density of overlying strata is $23 \mathrm{kN} / \mathrm{m}^{3}$, and the applied vertical stress is $10.5 \mathrm{MPa}$. The strike length of the model is $400 \mathrm{~m}$, and the mining design model is shown in Figure 6.

After the model is established, the coal seam excavation test is carried out. During coal seam excavation, $50 \mathrm{~m}$ boundary coal pillars are set on the left and right sides of the model, and the advancing length of coal seam is $300 \mathrm{~m}$ along the strike direction. The specific excavation model is shown in Figure 7. When the coal seams are mined in groups, the excavation of the lower group of coal seam is carried out 
TABLE 1: Mechanical parameters of coal and rock.

\begin{tabular}{lcccccc}
\hline $\begin{array}{l}\text { Rock } \\
\text { character }\end{array}$ & $\begin{array}{c}\text { Density } \\
\left(\mathrm{g} \cdot \mathrm{cm}^{-3}\right)\end{array}$ & $\begin{array}{c}\text { Modulus of elasticity } \\
(\mathrm{GPa})\end{array}$ & $\begin{array}{c}\text { Uniaxial compressive } \\
\text { strength }(\mathrm{MPa})\end{array}$ & $\begin{array}{c}\text { Tensile strength } \\
(\mathrm{MPa})\end{array}$ & $\begin{array}{c}\text { Cohesive strength } \\
(\mathrm{MPa})\end{array}$ & $\begin{array}{c}\text { Poisson's } \\
\text { ratio }\end{array}$ \\
\hline Mudstone & 2.40 & 9.6 & 8.6 & 1.86 & 1.66 \\
Siltstone & 2.51 & 12.8 & 26.5 & 2.83 & 0.35 \\
Fine & 2.47 & 16.2 & 20.2 & 2.51 & 2.53 & 0.32 \\
sandstone & & 20.5 & 46.7 & 5.37 & 2.36 & 3.65 \\
Glutenite & 2.55 & 3.5 & 11.2 & 2.05 & 0.30 \\
Coal & 1.37 & & & & 0.28 \\
\hline
\end{tabular}

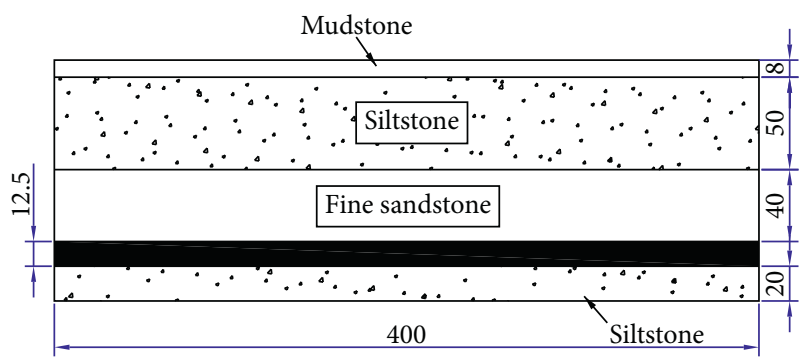

(a)

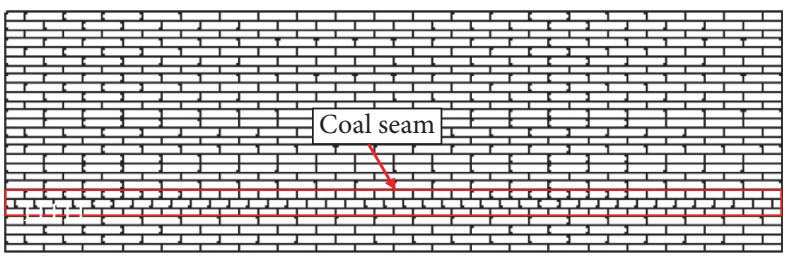

(b)

FIgURe 4: Coal mining model diagram of the upper group. (a) CAD design drawing. (b) UDEC model diagram.

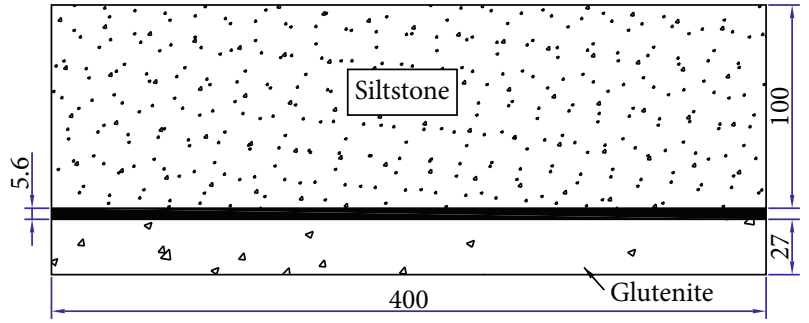

(a)

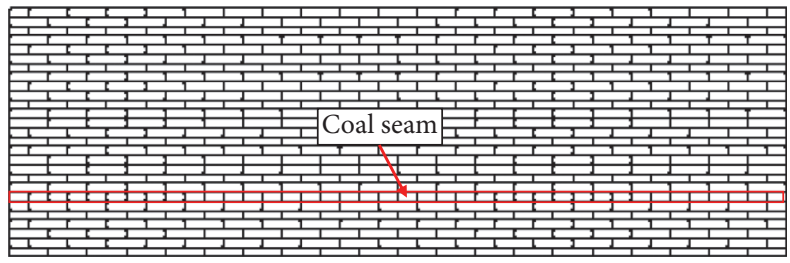

(b)

FIgURE 5: Coal mining model diagram of the lower group. (a) CAD design drawing. (b) UDEC model diagram.

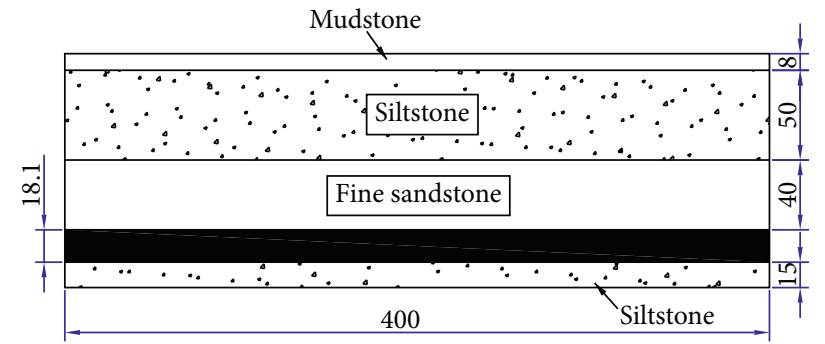

(a)

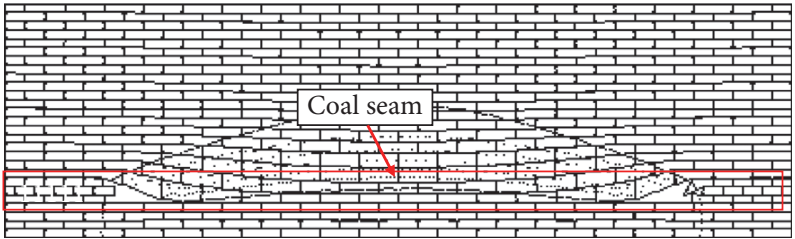

(b)

Figure 6: Model drawing of simultaneous mining of all coal seams. (a) CAD design drawing. (b) UDEC model diagram.

first, and the extension height of the water-conducting fracture zone of the overlying strata is analyzed. If the waterconducting fracture zone has no influence on the upper group coal during the mining of the lower group coal, the excavation of the upper group coal is carried out, and the expansion height of the water-conducting fracture zone during the mining of all coal seams is taken as the expansion height of the water-conducting fracture zone. When all coal seams are mined at the same time, all coal seams are regarded as a layer of coal for excavation, and the expansion height of water-conducting fracture zone during all mining is determined. 


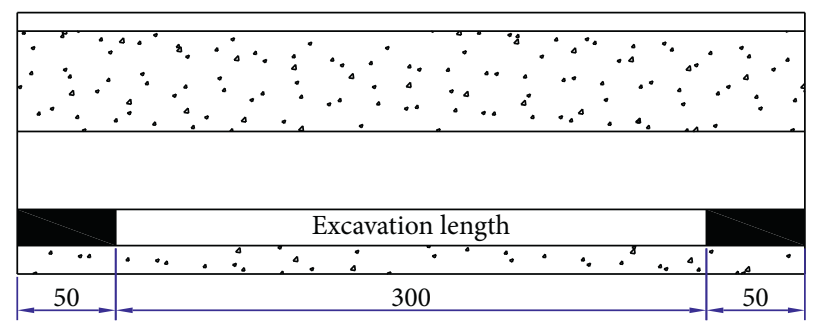

Figure 7: Excavation model.

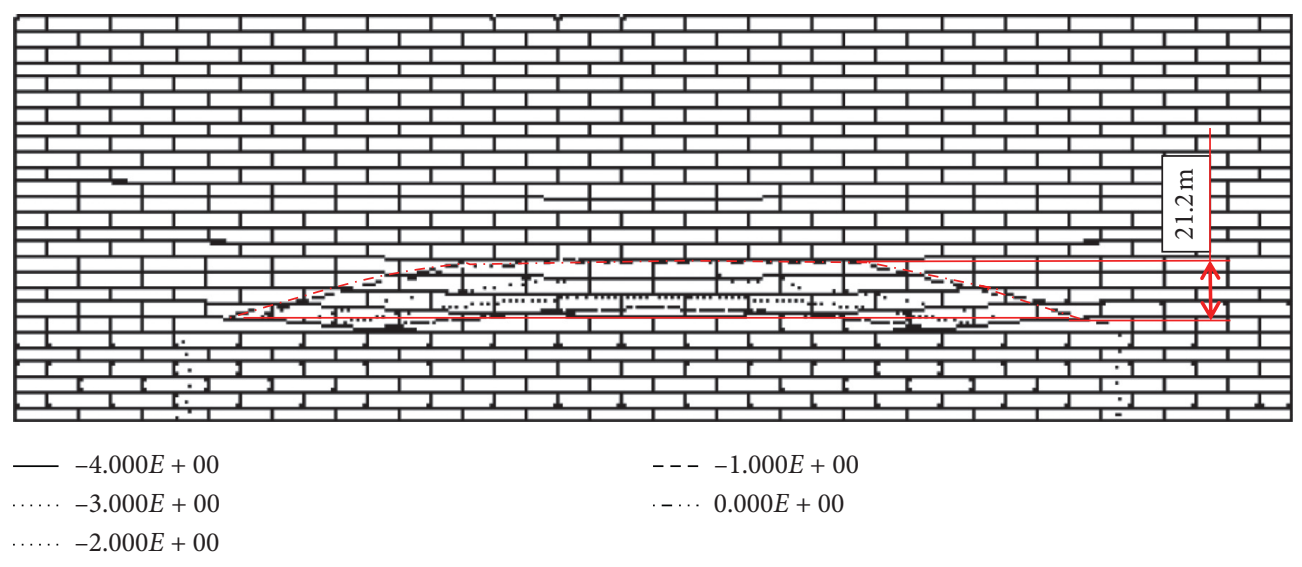

FIGURE 8: Caving and displacement evolution trend of overlying strata in the lower group coal mining.

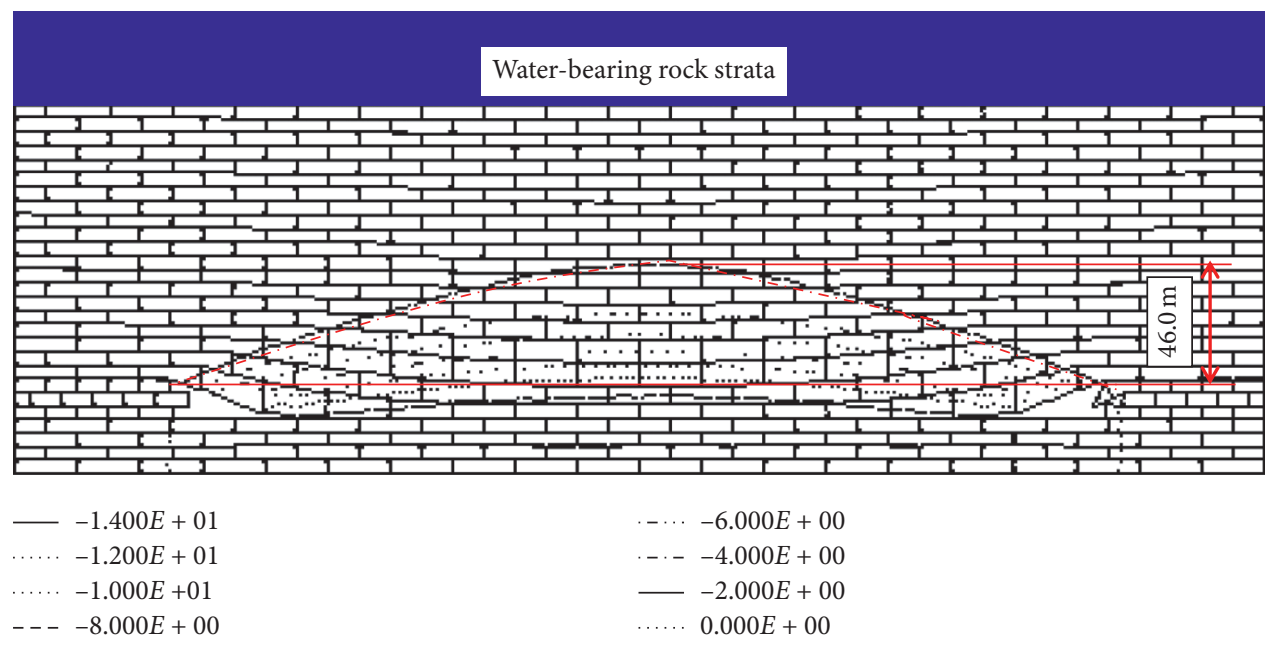

FIGURE 9: Caving and displacement evolution trend of overlying strata in the upper group coal mining.

\subsection{Analysis of Numerical Simulation Results}

4.2.1. Numerical Simulation Results of Grouping Mining. Figure 8 shows the evolution trend of movement and displacement of overlying strata in group coal mining under group coal mining simulation. It can be seen that, after the mining of the lower group of coal, the boundary line of 0 displacement of overlying strata moves to $21.2 \mathrm{~m}$ above the coal seam. If there is no movement of rock above 0 -displacement boundary line, the range from 0 -displacement to goaf can be regarded as the extension height of caving zone and water-conducting fracture zone, that is, the waterconducting fracture zone extends to $21.2 \mathrm{~m}$ above the lower group of coal seam during mining.

Figure 9 shows the evolution trend of movement and displacement of overlying strata in grouping simulation 


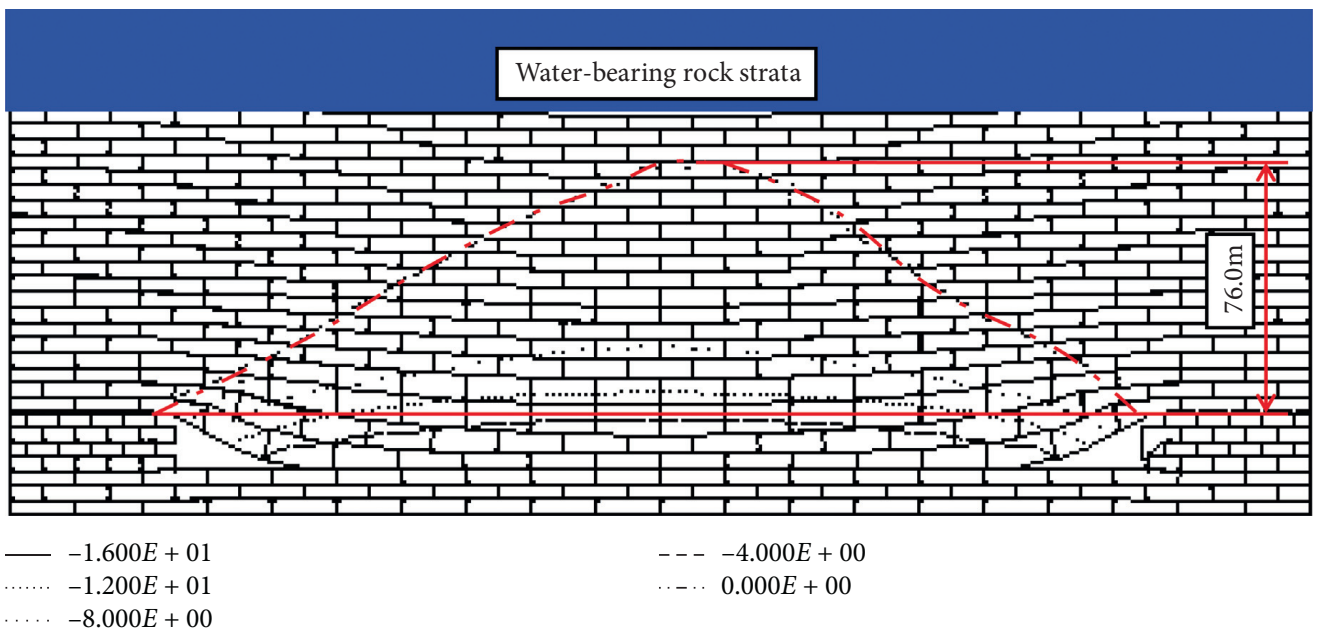

Figure 10: Caving and displacement evolution trend of overlying strata in all coal seams.

mining of upper group coal. It can be seen that the 0 -displacement boundary line of overlying strata movement after the upper group coal mining extends to $46 \mathrm{~m}$ above the coal seam, that is, the water-conducting fracture zone of the upper group coal mining extends to $46 \mathrm{~m}$ above the 8-1 coal.

\subsubsection{Numerical Simulation Results of Simultaneous Mining} of All Coal Seams. Figure 10 shows the evolution trend of displacement during simultaneous mining of all coal seams. It can be seen that after coal seam mining, the 0 -displacement boundary line of overlying strata extends to $76 \mathrm{~m}$ above coal seam, that is, the water-conducting fracture zone extends to $76 \mathrm{~m}$ above $8-1$ coal.

4.3. Results Analysis. According to formula (4), the height of water-proof coal (rock) pillar in numerical simulation of grouping mining is determined to be $56.08 \mathrm{~m}$ (calculated as $91.36 \mathrm{~m}$ ), and the height of water-proof coal (rock) pillar in simulation results of simultaneous mining of all coal seams is determined to be $86.36 \mathrm{~m}$ (calculated as $105.46 \mathrm{~m}$ ). The two simulation results are smaller than the height of waterconducting fractured zone calculated one.

For safety production, the height of the water-proof coal (rock) pillar is finally determined as $105.46 \mathrm{~m}$, which provides a basis for the design of the field working face.

\section{Conclusions}

(1) Establishing two schemes: grouping mining and simultaneous mining of all coal seams. Through theoretical analysis, it is concluded that the height of water-proof coal (rock) pillar in grouping mining is $91.08 \mathrm{~m}$ and that in simultaneous mining of all coal seams is $105.46 \mathrm{~m}$.

(2) UDEC numerical simulation software is used to design two models: grouping mining and simultaneous mining of all coal seams. It is determined that the height of water-proof coal (rock) pillar in grouping mining is $56.08 \mathrm{~m}$ and that in simultaneous mining of all coal seams is $86.36 \mathrm{~m}$.

(3) For safety production, the height of the water-proof coal (rock) pillar is finally determined as $105.46 \mathrm{~m}$, which provides a basis for the design of the field working face.

\section{Data Availability}

The data used to support the findings of this study are available from the corresponding author upon request.

\section{Conflicts of Interest}

The authors declare that there are no conflicts of interest regarding the publication of this paper.

\section{Acknowledgments}

This study was supported by the project funded by Huaneng Group Headquarters Science and Technology Project (Grant no. HNKJ19-H27).

\section{References}

[1] D. M. Yang, W. B. Guo, G. B. Gao et al., "Height of waterconducting zone in longwall top-coal caving mining under thick alluvium and soft overburden," Journal of China Coal Society, vol. 44, no. 11, pp. 3308-3316, 2019.

[2] Y. J. Song, J. P. Zuo, Y. B. Li et al., "Micro-seismic monitoring on fractured zone and water inrush mechanism analysis of deep mining above aquifer in Xingdong coalmine," Rock and Soil Mechanics, vol. 38, no. 8, pp. 2335-2342, 2017.

[3] X. F. Cheng and S. D. Liu, "Sound-wave CT detection for failure patterns of surrounding rock after mining," Journal of China Coal Society, vol. 26, no. 2, pp. 153-155, 2001.

[4] R. Feng, X. M. Lin, and Y. L. Tao, "Geotomographic research on cap rock destruction caused by mining coal seam," Chinese Journal of Geophysics, vol. 39, no. 1, pp. 114-124, 1996.

[5] W. Zhu, Y. H. Teng, and Z. X. Tang, "In-site study on development rule of fractured zone height by fully-mechanized 
mining in Lu'an Minefield," Coal Science and Technology, vol. 47 , no. 5, pp. 167-171, 2017.

[6] C. H. Huang, Study on Water Inrush Mechanism of Mining Fault, Central South University, Changsha, China, 2010.

[7] G. M. Yu, H. P. Xie, L. Yang et al., "Numerical simulation of fractal effect induced by activation of fault after coal extraction," Journal of China Coal Society, vol. 23, no. 4, pp. 396-400, 1998.

[8] B. Y. Li, "Down Three Zones' in the prediction of the water inrush from coalbed floor aquifer theory, Development and application," Journal of Shandong Institute of Mining and Technology (Natural Science Edition), vol. 18, no. 4, pp. 11-18, 1999.

[9] J. C. Zang, Y. Z. Zhang, and T. Q. Liu, Rock Mass Seepage and Water Inrush from Coal Floor, Geological Publishing House, Beijing, China, 1997.

[10] Z. G. Jing and B. Y. Li, "Preliminary discussion on the mechanism of water inrush from coal floor," Coalfield Geology and Exploration, vol. 2, no. 2, pp. 27-29, 1980.

[11] B. Y. Li and S. Z. Mi, Hydrogeology of Mining Engineering, Taian: Shandong Mining and Technology Press, Taian, China, 1988.

[12] Z. Y. Wang and H. Q. Liu, Coal Mining on Confined Water, Coal Industry Press, Beijing, China, 1992.

[13] X. Hu, L. Wang, Y. Lu, and M. Yu, "Analysis of insidious fault activation and water inrush from the mining floor," International Journal of Mining Science and Technology, vol. 24, no. 4, pp. 477-483, 2014.

[14] F. X. Jiang, "Stratum quality index and applications," Chinese Journal of Rock Mechanics and Engineering, vol. 13, no. 3, pp. 270-278, 1994.

[15] J. C. Zhao, T. Y. Tao, X. G. Liu et al., "On movement of strata and strata Pressure control in the fully mechanized mining with sublevel caving," Chinese Journal of Rock Mechanics and Engineering, vol. 16, no. 2, pp. 132-139, 1997.

[16] Y. C. Xu, "Design methods of the effective water-resisting thickness for the protective seam of the water barrier in fullycaving mechanized coal mining," Journal of China Coal Society, vol. 30, no. 3, pp. 305-308, 2005.

[17] Y. F. Gao, “"Our-zone” odel of rockmass movement and back analysis of dynamic displacement," Journal of China Coal Society, vol. 21, no. 1, pp. 51-56, 1996.

[18] J. M. Zhang, K. Zhang, Z. G. Cao et al., "Mining-bursting simulation and height calculation method for conductingwater fractured zone," Journal of China Coal Society, vol. 42, no. 6, pp. 1557-1564, 2017.

[19] J. Q. Jia, H. T. Wang, G. Z. Hu et al., "Methods of retaining water barrier and its stability analysis of steep working face," Journal of China Coal Society, vol. 34, no. 3, pp. 315-319, 2009.

[20] W. P. Huang, Y. F. Gao, B. Wang et al., "Evolution rule and development height of permeable fractured zone under combined-strata structure," Journal of Mining and Safety Engineering, vol. 34, no. 02, pp. 330-335, 2017.

[21] M. Yu, H. R. Gui, M. H. Li et al., "Testing study on mining of waterproof coal pillars in thick loose bed and thick coal seam under ultrathin overlying strata," Chinese Journal of Rock Mechanics and Engineering, vol. 23, no. 20, pp. 3494-3497, 2004.

[22] C. A. Tang, G. Y. Yu, H. Y. Liu et al., Numerical Experiment on Fracture and Strata Movement of Mining Rock Mass, Jilin University Press, Changchun, China, 2003.

[23] S. X. Yin, "Numerical simulation of influence of water barrier pillars for subsided column on rock failure in mining process," Journal of China Coal Society, vol. 31, no. 2, pp. 179-182, 2006.

[24] X. J. Li, Z. Wang, F. Lou et al., "Fracture characteristics and mining height of overlying strataunder water rich extra thick sand conglomerate," Mining Safety and Environmental Protection, vol. 45, no. 6, pp. 20-24, 2018.

[25] J. L. Xu and M. G. Qian, "Study on the quantitative analysis method for the experiment results of the mining-induced fracture," Journal of Liaoning Technical University, vol. 17, no. 6, pp. 586-589, 1998.

[26] M. G. Qian, J. L. Xu, and X. X. Miu, "Green technique in coal mining," Journal of China University of Mining \& Technology, vol. 32, no. 4, pp. 343-348, 2003.

[27] Y. G. Yang, J. Wang, and Y. J. Yu, "Effects of different coal safe mining sequence under river on height of water flowing fracture zone," Journal of China Coal Society, vol. 40, pp. 27-32, 2015.

[28] P. P. Chen, H. Q. Liu, and G. Y. Zhang, "Determination of waterproof rock pillar height with the top coal caving under sea," Journal of China Coal Society, vol. 34, no. 7, pp. 875-880, 2009.

[29] W. Q. Peng, W. J. Wang, and Q. F. Li, "Reasonable width of water-proof coal pillar under the condition of different fault dip angles," Journal of Mining and Safety Engineering, vol. 26, no. 2, pp. 179-182+186, 2009.

[30] T. Rangasamy, AR. Leach, and JV. Vuuren, "Current practice and guidelines for the safe design of water barrier pillars," Safe in Mines Research Advisory, Committee COL 702, 2001.

[31] X. C. Wang, F. C. Huang, and H. X. Zhang, "Discussion and improvement for A.H.Wilsons coal pillar design," Journal of China Coal Society, vol. 27, no. 6, pp. 604-608, 2002.

[32] L. Q. Shi, J. Han, T. B. Liu et al., "Study on design of safety pillar against water-inrush through stope sill faults," Chinese Journal of Rock Mechanics and Engineering, vol. 24, no. 2, pp. 5585-5590, 2005.

[33] Rules for Coal Pillar Setting and Coal Mining under Buildings, Water Bodies, Railways and Main Wells and Lanes, Coal Industry Press, Beijing, China, 2000. 